\title{
A Structure-Permeability Relationship of Ultrathin Nanoporous Silicon Membrane: A Comparison with the Nuclear Envelope
}

\author{
Eunkyoung Kim ${ }^{\dagger}$, Hui Xiong ${ }^{\dagger}$, Christopher C. Striemer ${ }^{\ddagger}$, David Z. Fang ${ }^{\ddagger}$, Philippe M. \\ Fauchet $^{\ddagger}$, James L. McGrath ${ }^{\S}$, and Shigeru Amemiya ${ }^{\ddagger}$ \\ Shigeru Amemiya: amemiya@pitt.edu \\ †Department of Chemistry, University of Pittsburgh, Pittsburgh, Pennsylvania 15260 \\ ¥Department of Electrical and Computer Engineering, University of Rochester, Rochester, New \\ York 14627
}

§Department of Biomedical Engineering, University of Rochester, Rochester, New York 14627

\begin{abstract}
We report on a simple, quantitative relationship between structure and permeability of a novel ultrathin nanoporous membrane based on nanocrystalline silicon. Large permeability of the freestanding nanomembrane to $\mathrm{Ru}\left(\mathrm{NH}_{3}\right)_{6}{ }^{3+}, \mathrm{O}_{2}$, or $1,1^{\prime}$ 'ferrocenedimethanol, which was able to be measured for the first time by employing scanning electrochemical microscopy, is proportional to density $\left(67 \mu \mathrm{m}^{-2}\right)$ and average radius $(5.6 \mathrm{~nm})$ of nanopores. As solution electrolyte concentration decreases down to $0.01 \mathrm{M}$, the nanopores are selectively "closed" against $\mathrm{Fe}(\mathrm{CN})_{6}{ }^{4-}$ because of electrostatic repulsion against negative charges at the pore wall. Permeability of the silicon nanomembrane was compared to permeability of the nuclear envelope to find that the channel diameter of the nuclear pore complex that perforates the nuclear envelope is much larger than the average diameter of the silicon nanopores and concomitantly a hypothetical diameter of $10 \mathrm{~nm}$.
\end{abstract}

Here we report on a structure-permeability relationship of a novel ultrathin nanoporous membrane based on nanocrystalline silicon. ${ }^{1}$ This silicon nanomembrane resembles a hypothetical model of the nuclear envelope, a nanoporous membranous organelle that separates the cytoplasm and nucleus of eukaryotic cells. Nucleocytoplasmic molecular transport across the nuclear envelope is mediated solely by the nuclear pore complex (NPC), which has been hypothesized as a water-filled cylindrical pore with $\sim 10 \mathrm{~nm}$ diameter. ${ }^{2}$ Recently, larger pore diameters and various gating mechanisms were proposed to explain puzzling transport selectivity of this important natural nanopore. ${ }^{2,3}$

The silicon nanomembrane was discovered as a new class of nanoporous membranes, ${ }^{1}$ which are nearly as thick $(10-15 \mathrm{~nm})$ as biological membranes. The ultrathin membrane with multiple cylindrical nanopores can be free-standing in aqueous solutions. The waterfilled short naopores with an average diameter of $\sim 5-25 \mathrm{~nm}$ can mediate size-selective transport of molecules up to $150 \mathrm{kDa}$, which will allow for highly efficient molecular filtration and dialysis. ${ }^{4}$ Ion-selective transport regulated by surface charges of the short nanopores was also observed in deionized water. Conventional transport experiments, however, did not provide information about how membrane structure affects transport

Correspondence to: Shigeru Amemiya, amemiya@pitt.edu.

Supporting Information Available: Details of SECM experiments and theory. These materials are available free of charge via the Internet at http://pubs.acs.org. 
dynamics, which was limited by slow diffusion of transported molecules in stagnant layers adjacent to the ultrathin membrane.

In this work, we establish a simple, quantitative relationship between structure and permeability of the ultrathin silicon nanomembrane. ${ }^{5}$ The membrane permeability was determined for the first time without diffusion limitation in stagnant layers by employing scanning electrochemical microscopy (SECM). We apply this relationship to assess ionselective transport dynamics at the silicon nanomembrane and also the hypothetical diameter of the NPC channel more quantitatively than in our previous work. ${ }^{6}$

Membrane transport of small redox molecules was studied using SECM-induced transfer mode at steady states. ${ }^{6,7}$ Both sides of a silicon nanomembrane were exposed to the identical solution of $0.1 \mathrm{M} \mathrm{KCl}$ and $1 \mathrm{mM} \mathrm{Ru}\left(\mathrm{NH}_{3}\right)_{6} \mathrm{Cl}_{3}$ (Figures 1a and $\mathrm{S} 1$ ). $\mathrm{Ru}\left(\mathrm{NH}_{3}\right)_{6}{ }^{3+}$ was reduced at the diffusion-limited rate at the tip of a disk-shaped Pt ultramicroelectrode with the radius, $a$, of $5 \mu \mathrm{m}$. As the SECM probe was scanned laterally at a constant height of $6 \mu \mathrm{m}$ from the membrane surface surrounded by the insulating silicon wafer, the tip current, $i_{\mathrm{T}}$, increased to a plateau and then returned to the original value (Figure 1b). The larger plateau current, which is close to the tip current in the bulk solution, $i_{\mathrm{T}, \infty}$, is due to a large membrane flux of $\mathrm{Ru}\left(\mathrm{NH}_{3}\right)_{6}{ }^{3+}$ from the bottom solution to the tip driven by a local gradient of a $\mathrm{Ru}\left(\mathrm{NH}_{3}\right)_{6}{ }^{3+}$ concentration under the tip. The tip displacement in this plateau current region agrees with a membrane size of $500 \mu \mathrm{m}$. The tip current is smaller above the insulating wafer surface, which hinders diffusion of $\mathrm{Ru}\left(\mathrm{NH}_{3}\right)_{6}{ }^{3+}$ to the tip. Importantly, a uniform, large plateau current can be observed only above membranes that were adequately wet with isopropanol when being immersed into the electrolyte solution (also for $\mathrm{Fe}(\mathrm{CN})_{6}{ }^{4-}$ in Figure 1b). A dry or an inadequately wet membrane gave a non-uniform, smaller response in line scans and images (Figure S3), where membrane transport was blocked by air bubbles trapped in the pores. ${ }^{8}$

Large permeability of the silicon nanomembrane to $\mathrm{Ru}\left(\mathrm{NH}_{3}\right)_{6}{ }^{3+}$ was determined from a plot of the steady-state tip current versus tip-membrane distance, $d$ (approach curve). As the tip was brought in $z$-direction to the center of the membrane, the tip current decreased only slightly and was much larger than the tip current above the wafer surface (Figure 1c). The experimental curve at the membrane fits well with a theoretical curve obtained by numerically solving an SECM diffusion problem with a membrane between two identical liquid phases (see Supporting Information). ${ }^{6,7 \mathrm{~b}}$ The membrane boundary condition was given by

$$
D\left[\partial c_{1}(r, z) / \partial z\right]_{z=0}=D\left[\partial c_{2}(r, z) / \partial z\right]_{z=0}=k\left[c_{1}(r, 0)-c_{2}(r, 0)\right]
$$

where $D$ is a diffusion coefficient of redox molecules (actual values are listed in Supporting Information), $c_{1}(r, z)$ and $c_{2}(r, z)$ are their concentrations in the top and bottom solutions, respectively, and $k$ is membrane permeability. Permeability of $0.060 \mathrm{~cm} / \mathrm{s}$ obtained from the fit is $\sim 60$ times larger than a mass transport rate expected in stagnant layers $\left(\sim 10^{-3} \mathrm{~cm} / \mathrm{s}\right),{ }^{1}$ thereby requiring SECM for determination of this large permeability. The approach curve with $\mathrm{Ru}\left(\mathrm{NH}_{3}\right)_{6}{ }^{3+}$ overlaps with approach curves with neutral molecules, 1,1'-

ferrocenedimenthanol (Figure $1 \mathrm{~b}$ ) and $\mathrm{O}_{2}$, yielding the same dimensionless permeability, $\mathrm{kal}$ $D=4$. Importantly, a simulated concentration profile of mediator molecules corresponds to a hemispherical diffusion field at the tip, which evolves across the membrane into the bottom solution. This result indicates that overlapping of a local diffusion field at each nanopore results in the micrometer-scale diffusion field. ${ }^{6}$

According to effective medium theories, ${ }^{9}$ permeability based on the uniform membrane model (eq 1) can be related to the density, $N$, and average effective radius, $r_{\text {eff }}$, of randomly 
distributed nanopores when the membrane is negligibly thin, thereby yielding (see Supporting Information)

$$
k=2 D N r_{\text {eff }}
$$

This structure-permeability relationship is valid for $\mathrm{Ru}\left(\mathrm{NH}_{3}\right)_{6}{ }^{3+}, \mathrm{O}_{2}$ and 1,1'ferrocenedimenthanol. A $N r_{\text {eff }}$ value of $0.40 \mu \mathrm{m}^{-1}$ as obtained from $k$ values of these redox molecules using eq 2 is very close to a value of $0.38 \mu \mathrm{m}^{-1}$ with $N=67 \mu \mathrm{m}^{-2}$ and an average actual pore radius, , of $5.6 \mathrm{~nm}$ determined from TEM images of the membrane (see Supporting Information). This agreement validates the assumption that the membrane is negligibly thin, which implies that translocation of the redox molecules through the short pore (green arrows in Figure 1a) does not limit the membrane permeability. Thus, membrane permeability is controlled by diffusion of molecules to the pore entrance (red arrows). In fact, length of the latter diffusion path characterized by distance between edges of neighboring pores $\left(\sim 2 /(\pi N)^{1 / 2}-2 r=127 \mathrm{~nm}\right)$ is much larger than nanopore length of 15 $\mathrm{nm}$. In contrast to the membrane permeability based on $\sim 5.3 \times 10^{3}$ nanopores under the 10 $\mu \mathrm{m}$-diameter SECM probe, single pore permeability is governed by the pore translocation. ${ }^{10}$

We found that $\mathrm{Fe}(\mathrm{CN})_{6}{ }^{4-}$ transport is slower than expected from eq 2 with the $N$ and $r^{-}$ values and becomes even slower at a lower $\mathrm{KCl}$ concentration as demonstrated by more negative approach curves (Figure $2 \mathrm{a} ; k=0.026,0.013$, and $0.0052 \mathrm{~cm} / \mathrm{s}$ in $0.1,0.03$ and 0.01 $\mathrm{M} \mathrm{KCl}$, respectively). No effect of the electrolyte concentrations on $\mathrm{Ru}\left(\mathrm{NH}_{3}\right)_{6}{ }^{3+}$ transport (overlapping approach curves in Figure 2a) or 1,1'-ferrocenedimethanol transport was observed. These results indicate that $\mathrm{Fe}(\mathrm{CN})_{6}{ }^{4-}$ transport is slowed down by a double layer effect based on electrostatic repulsion between $\mathrm{Fe}(\mathrm{CN})_{6}{ }^{4-}$ and negative charges on $\mathrm{SiO}_{2}{ }^{-}$ covered membrane/pore surface. ${ }^{1}$ In contrast to complete impermeability in deionized water, ${ }^{1}$ the $\mathrm{Fe}(\mathrm{CN})_{6}{ }^{4-}$ permeability is still high in $0.1-0.01 \mathrm{M} \mathrm{KCl}$, where Debye length of $1.0-3.0 \mathrm{~nm}^{11}$ is smaller than the actual pore radius. This result indicates that a silicon nanopore is non-uniformly permeable to $\mathrm{Fe}(\mathrm{CN})_{6}{ }^{4-}$, which can diffuse through the pore center while being excluded from the double-layer region near the negatively-charged pore wall. ${ }^{8} \mathrm{We}$ approximately estimated an effective radius of the central pore opening from the $\mathrm{Fe}(\mathrm{CN})_{6}{ }^{4-}$ permeability using eq 2 with the $N$ value of $67 \mu \mathrm{m}^{-2}$ to find that resulting $r_{\text {eff }}$ values are still larger than $0.44 \mathrm{~nm}^{12}$ radius of $\mathrm{Fe}(\mathrm{CN})_{6}{ }^{4-}$ (Figure $2 \mathrm{~b}$ ). Also, the double-layer region within which $\mathrm{Fe}(\mathrm{CN})_{6}{ }^{4-}$ is excluded was approximated to have the thickness of $r=$ $r_{\text {eff }}$, which is nearly twice larger than Debye length (Figure $2 b$ ).

The silicon nanomembrane is much less permeable than the nuclear envelope at the nucleus of a Xenopus laevis oocyte, where permeability to small redox molecules was limited by their diffusion in the bulk nucleus even using a $2 \mu$ m-diameter SECM probe. ${ }^{6}$ Since the silicon nanopores are denser and shorter than the NPC of this nuclear envelope, ${ }^{3 \mathrm{a}}$ the diameter of the NPC channel should be larger than the average diameter of $11.6 \mathrm{~nm}$ at silicon nanopores and concomitantly the hypothetical diameter of $10 \mathrm{~nm}$. This finding supports recent models that the NPC possesses a 40-45 nm-diameter pore, where the inner wall is modified with a peptide nanostructure that is permeable to molecules smaller than $10-40 \mathrm{kDa}^{3 \mathrm{~b}, \mathrm{~d}}$ Our result, however, does not exclude possibility that small molecules may permeate also through peripheral channels of the $\mathrm{NPC},{ }^{3 a, e}$ thereby resulting in an apparently larger channel diameter.

In conclusion, we established a structure-permeability relationship of the silicon nanomembrane. The permeability of the ultrathin membrane is determined by $N r_{\text {eff }}$ rather than its porosity, $\pi N r_{\text {eff }}{ }^{2}$. Significance of this relationship was demonstrated in mechanistic and biological studies of nanopore-mediated membrane transport. 


\section{Supplementary Material}

Refer to Web version on PubMed Central for supplementary material.

\section{Acknowledgments}

This work was supported by the National Institutes of Health (GM073439) and the Petersen Institute of NanoScience and Engineering at the University of Pittsburgh. We thank Thomas R. Gaborski for valuable suggestions.

\section{References}

1. Striemer CC, Gaborski TR, McGrath JL, Fauchet PM. Nature. 2007; 445:749. [PubMed: 17301789]

2. Terry LJ, Shows EB, Wente SR. Science. 2007; 318:1412. [PubMed: 18048681]

3. (a) Fahrenkrog B, Aebi U. Nat. Rev. Mol. Cell Biol. 2003; 4:757. [PubMed: 14570049] (b) Frey S, Richter RP, Goerlich D. Science. 2006; 314:815. [PubMed: 17082456] (c) Melcak I, Hoelz A, Blobel G. Science. 2007; 315:1729. [PubMed: 17379812] (d) Lim RYH, Fahrenkrog B, Koser J, Schwarz-Herion K, Deng J, Aebi U. Science. 2007; 318:640. [PubMed: 17916694] (e) Beck M, Lucic V, Forster F, Baumeister W, Medalia O. Nature. 2007; 449:611. [PubMed: 17851530]

4. Kooman JP, van der Sande FM, Leunissen KML. Blood Purification. 2007; 25:377. [PubMed: 17785967]

5. A similar relationship based on theory of particles diffusing to a partially absorbing surface ${ }^{5 \mathrm{a}}$ was demonstrated in an SECM study of nanometer-sized defects in solid-supported self-assembled monolayers. ${ }^{5 b}$ Berg HC. Random Walks in Biology. 1993Princeton, NJPrinceton University Press: 30-36. Forouzan F, Bard AJ, Mirkin MV. Isr. J Chem. 1997; 37:155.

6. Guo J, Amemiya S. Anal. Chem. 2005; 77:2147. [PubMed: 15801749]

7. (a) Yamada H, Matsue T, Uchida I. Biochem. Biophys. Res. Commun. 1991; 180:1330. [PubMed: 1953784] (b) Barker AL, Macpherson JV, Slevin CJ, Unwin PR. J. Phys. Chem. B. 1998; 102:1586.

8. Ho C, Qiao R, Heng JB, Chatterjee A, Timp RJ, Aluru NR, Timp G. Proc. Natl. Acad. Sci. U.S.A. 2005; 102:10445. [PubMed: 16020525]

9. Makhnovskii YA, Berezhkovskii AM, Zitserman VY. J. Chem. Phys. 2005; 122236102 and references cited therein.

10. (a) Macpherson JV, Jones CE, Barker AL, Unwin PR. Anal. Chem. 2002; 74:1841. [PubMed: 11985316] (b) Ervin EN, White HS, Baker LA, Martin CR. Anal. Chem. 2006; 78:6535. [PubMed: 16970331]

11. Bard, AJ.; Faulkner, LR. Electrochemical Methods. Fundamentals and Applications. 2nd ed.. New York: Wiley; 2001. p. 549

12. Marcus Y. Pure Appl. Chem. 1987; 59:1093. 
(a)
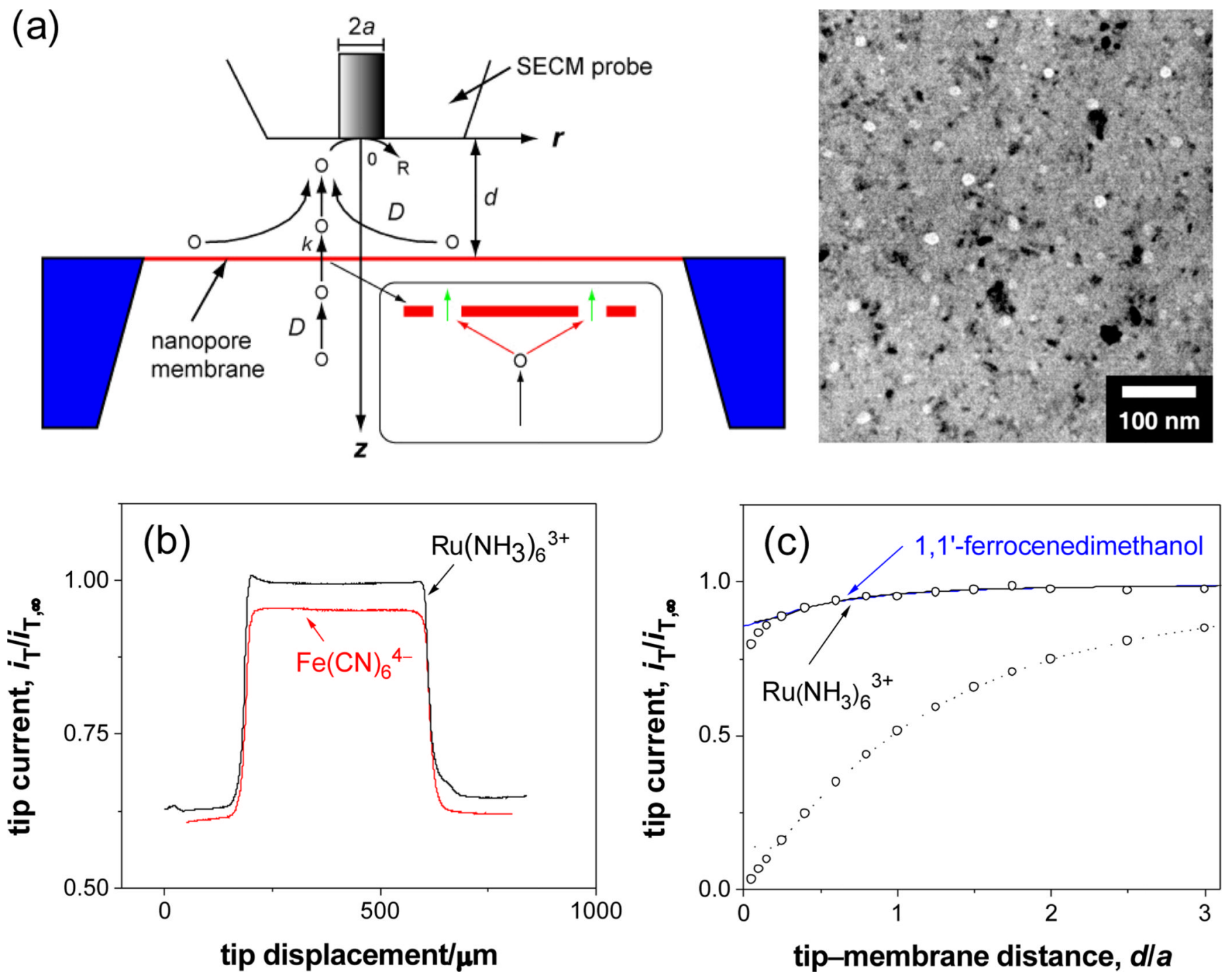

Figure 1.

(a) Scheme of SECM-induced transfer of redox molecules across a nanomembrane with its TEM image, where the bright circles are pores and the dark spots are diffracting nanocrystals. The inset shows microscopic diffusion paths of transported molecules $\mathrm{O}$ at the membrane. (b) Line scans and (c) approach curves at the membrane (solid lines). In (c), circles represent simulated approach curves and the dotted line is an approach curve with $\mathrm{Ru}\left(\mathrm{NH}_{3}\right)_{6}{ }^{3+}$ at the wafer surface. 

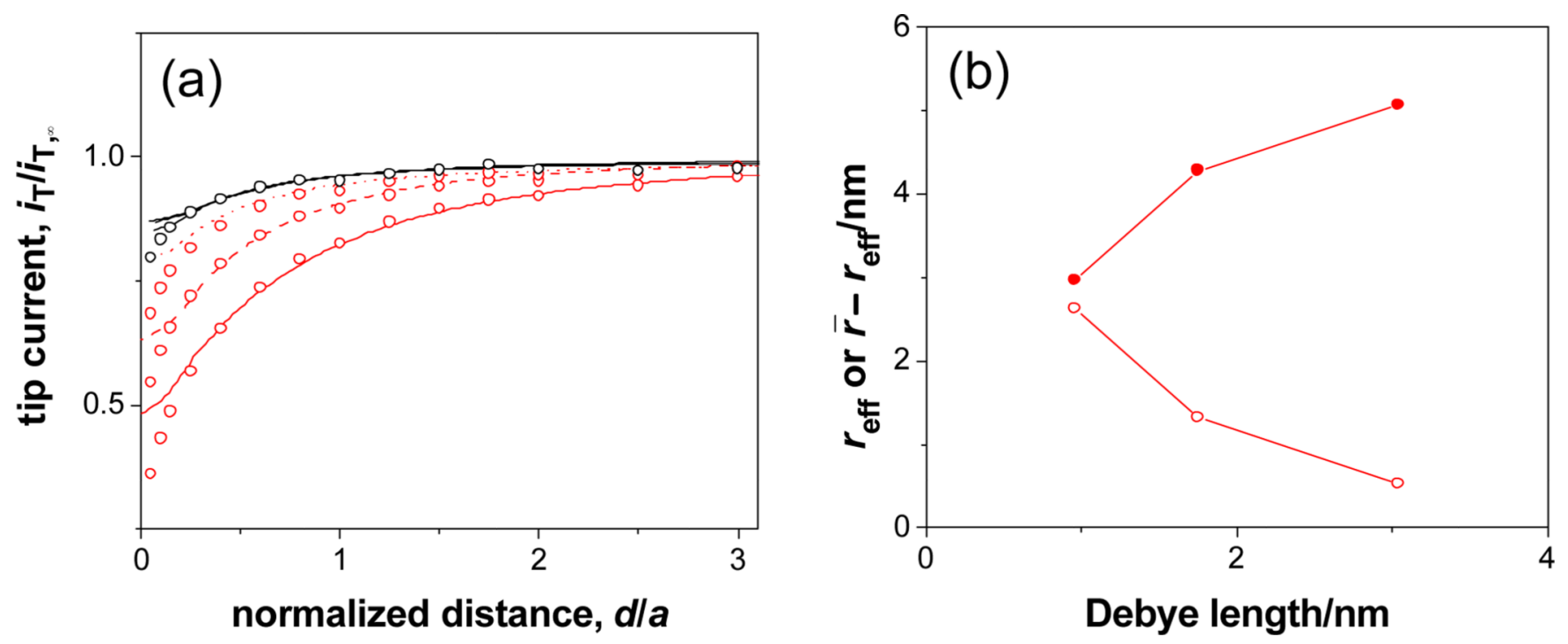

Figure 2.

(a) Approach curves at a silicon nanomembrane in 0.1 (dotted line), 0.03 (dashed line), and 0.01 (solid line) $\mathrm{M} \mathrm{KCl}$ with $1 \mathrm{mM} \mathrm{K}_{4} \mathrm{Fe}(\mathrm{CN})_{6}$ (red) or $\mathrm{Ru}\left(\mathrm{NH}_{3}\right)_{6} \mathrm{Cl}_{3}$ (black). Circles represent simulated approach curves. (b) Corresponding Debye-length dependence of $r_{\mathrm{eff}}(\circ)$ and $r-r_{\text {eff }}(\bullet)$ for $1 \mathrm{mM} \mathrm{K} 4 \mathrm{Fe}(\mathrm{CN})_{6}$. 